\title{
O OS DITOS E NÃO DITOS SOBRE A PRÁTICA DO SUPERVISOR NO CONTEXTO DAS ESCOLAS DA EDUCAÇÃO DE JOVENS E ADULTOS-EJA
}

\author{
Diane Mendes Feitosa ${ }^{1}$ \\ Maria da Glória Carvalho Moura ${ }^{2}$
}

\begin{abstract}
Resumo
Este artigo é o resultado de uma pesquisa de natureza qualitativa do tipo descritiva que teve como objetivo analisar a ação supervisora e sua contribuição para a produção de saberes e práticas escolares na educação de pessoas jovens e adultas. A proposta teve como suporte teórico autores como: Moura (2006), Alarcão (2003, 2004), Saviani (2002), Rangel (2002), Medina (2002) e Brasil (1999, 2000). Para tanto, realizou-se uma investigação com catorze professores, sete diretores e sete supervisores que atuam em sete escolas da rede pública municipal de Teresina- PI. Elegemos a entrevista semiestruturada como instrumento de recolha dos dados por ser considerada importante estratégia para obtenção de informações para estudos desta natureza. No tratamento dos dados foi utilizada a técnica da análise do discurso, tendo como suporte teórico as ideias de Pêcheux (2008) e Orlandi (2007, 2009). De acordo com o estudo coexistem diferentes concepções sobre a ação supervisora ocasionando a indefinição quanto ao seu objeto de trabalho e principalmente restringindo a sua contribuição para a transformação das práticas desenvolvidas na escola. Os resultados revelam, ainda, que a realização de atividades burocráticas é apontada como principais empecilhos encontrados pela supervisão escolar para a promoção de momentos estimuladores da reflexão da prática docente evidenciando que a ação supervisora no contexto escolar não tem conseguido fomentar ou apoiar o processo reflexivoformativo dos professores de EJA.
\end{abstract}

Palavras chave: Supervisão escolar. Educação de jovens e adultos. Formação docente. Práticas pedagógicas.

\section{THE SAID AND NOT TOLD ABOUT THE PRACTICE OF SUPERVISOR IN THE CONTEXT OF SCHOOLS OF EDUCATION ADULTS AND YOUNG EDUCATION (AJE)}

\begin{abstract}
This article is the result of a qualitative nature of descriptive aimed to analyze the action supervisor and their contribution to the production of knowledge and school practices in of adults and young education (AJE). The proposal had as a theoretical support authors as Moura (2006) Alarcão (2003, 2004), Saviani (2002), Rangel (2002), Medina (2002) and Brazil (1999, 2000). Thus, we performed an investigation with fourteen teachers, seven principals and seven supervisors working in seven municipal public schools of Teresina-PI. Elect the semi-structured interview as a tool for collecting data to be considered an important strategy for obtaining information for studies of this nature. In the data the technique of discourse analysis with theoretical support ideas Pecheux (2008) and Orlandi (2007, 2009), was used. According to study co-exist different views on supervisory action leading to uncertainty as to the object of his work and mostly restricting its contribution to the transformation of the practices developed at school. The results also show that the performance of bureaucratic activities is identified as the main obstacles encountered by school supervision to promote stimulating moments of reflection of teaching practice supervisor indicating that the action in the school context has failed to encourage or support the reflective process-training of teachers of adults and young education (AJE).
\end{abstract}

Keywords: School supervision. Education of youth and adults. Teacher education. Pedagogical practices Reflexões iniciais

\footnotetext{
${ }^{1}$ Mestre em educação pela Universidade Federal do Piauí-UFPI. Membro do Núcleo Interdisciplinar de Pesquisa e práticas Curriculares e Formação de profissionais da Educação - NIPPC- UFPI. Professora da rede estadual de ensino. E-mail: diane.feitosa@yahoo.com.br

${ }^{2}$ Professora permanente do programa de pós-graduação em educação da UFPI. Coordenadora do Núcleo interdisciplinar de Pesquisa e práticas Curriculares e Formação de profissionais da Educação - NIPPC UFPI. Coordenadora do Comitê Gestor Institucional de Formação Inicial e Continuada dos profissionais da educação Básica. E-mail: glorinha m@yahoo.com.br
} 
As transformações econômicas, políticas e culturais oriundas das sociedades contemporâneas repercutem diretamente nas demandas sociais e políticas exigindo que se reexaminem constantemente as questões educacionais no sentido de garantir uma formação que possibilite ao homem desenvolver todas as suas potencialidades.

Nesse processo a escola enfrenta, como instituição formadora, desafios que se fazem sentir em todos os setores da sociedade, assumindo importância à medida que permite a interação sistematizada e organizada dos sujeitos com os conhecimentos acumulados pela humanidade. Desta forma, a função educativa da escola contemporânea vai além da ideia de transmitir informações, deve orientar para que haja a formulação de novas estratégias que transformem o cotidiano escolar de modo que os educandos possam vivenciar práticas sociais "que induzam à solidariedade, à colaboração, à experimentação compartilhada, assim como a outro tipo de relações com o conhecimento e com a cultura que estimulem a busca, a comparação, a crítica, a iniciativa e a criação" (GÓMES PÉREZ, 1998, p. 26).

Para tanto, é necessário um novo projeto de escola, outras formas de construção do saber e principalmente uma reflexão sobre as pedagógicas nos espaços escolares no sentido de responder às necessidades de crianças, jovens e adultos que vivem nessas sociedades cada vez mais complexas.

No bojo dessas discussões destacam-se as intervenções pedagógicas do supervisor escolar, compreendidas em uma concepção ampla, como elemento que faz parte explicitamente do processo educativo e que contribui para a organização do trabalho escolar à medida que desenvolve uma variedade de atividades e propiciam "[...] orientação e assistência aos professores nas dificuldades que enfrentam no seu cotidiano escolar, mantendo com eles um relacionamento próximo num ambiente de colaboração e respeito mútuo" (ALONSO, 2002, p. 17).

Os debates sobre a supervisão escolar ressurgem com força, não apenas como atividade relacionada à organização do trabalho escolar, voltada para o desempenho do professor na sala de aula, sobretudo, vista sob outro ângulo, um novo olhar, uma supervisão institucionalizada que amplia o seu campo de atuação e forma de pensar a escola como organização coletiva que necessita, portanto, de uma reflexão em uma visão, macro intra e extraescolar.

Caminhando nessa direção, este artigo volta-se para questões relativas à prática do supervisor escolar que atua nas escolas de Educação de Jovens e Adultos-EJA, percorrendo situações desafiadoras através da interação com a realidade educacional. A partir desta compreensão, o objetivo deste trabalho foi investigar a ação supervisora e sua contribuição para a produção de saberes e práticas escolares na educação de pessoas jovens e adultas. Para tanto, realizou-se uma investigação junto a professores, diretores e supervisores que atuam em escolas da rede pública municipal de Teresina, capital do Estado do Piauí. A pesquisa tem base descritiva, 
natureza qualitativa, considerando as concepções dos sujeitos sobre a problemática evidenciada no seu contexto de atuação.

Para melhor sistematização das discussões, o texto traz inicialmente as concepções e atribuições da supervisão que emergem no cenário das sociedades contemporâneas, refletindo sobre a prática pedagógica dos supervisores que trabalham, especificamente, no âmbito das escolas que atuam com a educação de pessoas jovens e adultas, objeto deste estudo. Em seguida, traçou-se o caminho metodológico utilizado na investigação, e por fim apresentam-se as análises dos dados obtidos após a realização de entrevista semiestruturada com supervisores, professores e diretores da educação básica que atuam com pessoas jovens e adultas.

\section{Tecendo caminhos para a supervisão escolar na contemporaneidade}

No decorrer da história da educação do Brasil, ocorreram mudanças no conceito de educação, escola, sociedade e no papel dos diversos agentes educacionais, dentre eles, o supervisor escolar. Diante dessa nova realidade que se impõe, os supervisores são desafiados a trabalhar para a construção de mudanças na educação e, consequentemente, no contexto escolar. São exigidos o desenvolvimento de competências técnicas, políticas, administrativas e pedagógicas, e isso requer formação que motive a realização de pesquisas sobre temas educacionais, aprofundando estudos sobre as áreas específicas do cotidiano escolar e especificamente no campo da supervisão em EJA, foco deste estudo, visto que o contexto exige profissionais informados, críticos, propositivos, que apostem no protagonismo dos sujeitos sociais.

Autores como Amaral, Moreira, Ribeiro (1996), Alarcão (2004), Alonso (2002), Rangel (2002), Medina (2002), Filipkowski (2003), Ferreira (2004) e outros, abordam aspectos que esclarecem o papel do supervisor como mediador do desenvolvimento profissional docente. Registre-se, para ilustrar, que na sua relação com o professor contribui sobremaneira para a construção de saberes significativos, capazes de desencadear uma nova cultura profissional e mudanças efetivas nas organizações escolares.

Neste sentido, Alarcão; Tavares (2003, p. 154) afirmam:

O supervisor escolar é aquele sujeito responsável pela dinamização e acompanhamento do desenvolvimento qualitativo da organização escolar e dos que nela realizam o seu trabalho de estudar, ensinar ou apoiar a função educativa, através de aprendizagens individuais e colectivas, incluindo as dos novos agentes.

Filipkowski (2003) também se pronuncia sobre essa questão, apontando o supervisor escolar ou coordenador pedagógico como profissional que coordena as ações e a proposta de formação continuada do professor, tendo em vista que está em contínuo contato com estes, 
exercendo uma função de apoio, acompanhamento e orientação das atividades pedagógicas promovendo, portanto, a atualização e o estudo das práticas coletivas no contexto escolar.

Essa perspectiva apontada pelo autor supracitado coloca o supervisor como corresponsável pela formação continuada dos docentes, considerando que esta é uma tarefa de todos os agentes educacionais. É útil lembrar que a organização escolar não se restringe à soma de práticas justapostas "[...] a interação de cada membro com uma meta comum define o fenômeno da participação" (PACHECO, 2008, p. 41). Desta forma, cada educador é também responsável por seu processo de desenvolvimento pessoal e profissional. E assim sendo, o supervisor precisa conquistar seu espaço "[...] como alguém com capacidade de apoio, que impulsiona o grupo com o qual trabalha, através de um posicionamento mais crítico em relação à realidade escolar e global" (FILIPKOWSKI, 2003, p. 51).

O contexto escolar que educa, no qual o sujeito (professor) está permanentemente em formação, ao supervisor é conferida a tarefa de promover reflexões coletivas em torno de temáticas educacionais capazes de provocar uma constante avaliação da prática docente, não se resume apenas à troca de experiências, mas se torna um momento de reflexão-ação-reflexão, tendo como produção final a construção do conhecimento e a transformação da ação docente.

Nesse sentido, o supervisor escolar torna-se o mediador do trabalho desenvolvido em sala de aula, contribuindo para práticas escolares reflexivas e, consequentemente, com uma escola reflexiva "[...] onde cada elemento é individualmente responsável pelos atos do coletivo" (PACHECO, 2008, p. 41). O papel do supervisor, nesse cenário, constitui-se um parceiro políticopedagógico do professor propiciando momentos de reflexão e sistematização da formação continuada da equipe docente, legitimando o espaço escolar como verdadeiramente vivo e democrático.

Em face ao exposto, o núcleo das atribuições do supervisor escolar é realizar a formação continuada em serviço, assumindo posturas que permitam problematizações e ações realizadas no dia a dia escolar, articuladas com temas da prática real refletidas em um ambiente de participação coletiva, que estimulam o processo de tomada de decisões sobre o fazer pedagógico. Para tal intento é necessário que organize situações em que o professor investigue a sua própria prática, modificando o modelo de formação baseado em práticas de investigação sobre os professores, para investigações com e pelos professores (NÓVOA, 1995).

Nesse sentido, o modelo de formação é pautado na integração e articulação de momentos de aprendizagens que ultrapassem a preocupação com a dimensão instrumental da profissão, tornando-os profissionais com posturas reflexivas em condições de visualizar sua prática como uma ação mobilizadora de saberes docentes. Entre os dilemas e possibilidades impostos ao ato de ensinar 
diante do novo contexto educacional contemporâneo, percebe-se que vem se consolidando um novo paradigma de formação que vislumbra o professor como produtor de conhecimentos a partir da sua prática (BRITO 2005).

Moura (2006), pesquisadora das práticas do professor e, em especial da EJA, aponta para a necessidade de uma formação continuada em espaços de reflexão e colaboração que propiciem a troca de experiências, que provoquem a tematização da prática docente, ressignificando o fazer profissional através dos saberes e das vivências da sala de aula por acreditar que a escola é um espaço legítimo de formação, no qual se aprende com os outros agregando valores individuais e transformando-os em um projeto coletivo, onde todos os envolvidos são sujeitos em formação. Portanto, são ensinantes e aprendentes; são educadores em uma escola que educa.

Nóvoa (2008) vem nos dizer que diante dessa nova configuração de sociedade que ora se apresenta, as soluções do passado não respondem mais às questões do presente. Diante disso, os professores encontram-se em frente a três dilemas: a necessidade de reconstruir um laço forte com o espaço comunitário; capacidade de repensar o trabalho docente em busca da autonomia e o dilema do conhecimento, que diz respeito à construção e reconstrução deste, a partir da reflexão crítica da prática.

De acordo com o autor supracitado, é imprescindível que o professor desenvolva a consciência de que seu conhecimento profissional não se resume a técnicas de ensino e conteúdos disciplinares. O conhecimento profissional é produzido, sobretudo, nos espaços de discussão, no processo deliberativo e de reflexão sobre a prática docente em um movimento contínuo de "saber analisar" e "saber analisar-se".

Diante desse novo desafio, cabe ao supervisor escolar desenvolver a capacidade para realizar pesquisas sobre temas educacionais, que aprofundem estudos sobre os problemas do cotidiano escolar. Para tanto, requer profissionais informados, críticos, reflexivos, propositivos que apostem no protagonismo dos sujeitos envolvidos no processo educativo e que possam "[...] desencadear ou fazer a leitura dos desafios e apoiar pessoas no processo de aprendizagem, no seu próprio ou dos outros" (ALARCÃO, 2004, p. 37). É necessário, sobretudo, mobilizar saberes para agir em determinadas situações, ou seja, suscitar a reflexão e aprendizagem em grupo para maior entendimento da relação teoria e prática. Cabe ao supervisor da educação de jovens e adultos:

[...] Possibilitar aos professores que atuam na educação de jovens e adultos a compreensão da importância do uso de instrumentos que os auxiliem em sua prática de sala de aula e dêem suporte ao desenvolvimento do processo de ensinoaprendizagem (BRASIL, 1999, p. 41). 
Em face aos diferentes desafios impostos aos educadores, a prática constitui o ponto de partida e o ponto de chegada para a utilização e produção de saberes profissionais, necessários para as intervenções no cotidiano das instituições escolares. No que se refere especificamente à ação do supervisor na EJA, entende-se que também possui, utiliza e produz conhecimentos ao realizar seu trabalho de parceria pedagógica com o professor.

\section{Contextualizando o percurso da pesquisa}

Neste texto apresentam-se os resultados obtidos na dissertação de mestrado na qual se realizou uma pesquisa de natureza qualitativa em que se analisaram os significados atribuídos pelos sujeitos investigados ao trabalho desenvolvido pela ação supervisora, com profissionais que atuam na educação básica com a Educação de Jovens e Adultos - EJA, em contextos diferenciados, ou seja, o espaço de vivência dos partícipes no interior da escola.

A opção pela pesquisa com abordagem qualitativa justifica-se pela identificação com o objeto de estudo, visto que, esse estudo se constitui “[...] um processo de reflexão e análise da realidade através da utilização de métodos e técnicas para compreensão detalhada do objeto de estudo em seu contexto histórico ou segundo a sua estruturação" (OLIVEIRA, 2007, p. 37). Isso significa dizer que a pretensão da investigação é a compreensão da ação supervisora no contexto escolar, por meio do olhar dos profissionais que a vivenciam no dia a dia da escola.

No sentido de alcançar o objetivo proposto, a pesquisa foi realizada em sete escolas da rede pública municipal da cidade de Teresina -Piauí tendo como partícipes 14 supervisores, 07 professores e 07 diretores que atuam na educação básica na modalidade Educação de Jovens e Adultos- EJA. Para efeito desse estudo a ênfase é dada à fala dos interlocutores, que passam ser identificados no texto pelas seguintes iniciais: "P" para professores, "S" supervisores e "D" diretores, seguidos de respectivos pseudônimos.

A entrevista foi utilizada como instrumento de recolha de dados por ser considerado um importante instrumento para obtenção de subsídios reais da amostra pesquisada. Desta forma, a entrevista possibilitou compreender, do ponto de vista discursivo, aspectos relacionados à ação supervisora na EJA, considerando a reflexividade e a produção de saberes, priorizando a voz dos interlocutores permitindo apreender as suas aspirações, as atitudes, crenças e valores, inserindo-os no centro da pesquisa.

A organização dos dados foi pautada no procedimento de categorização das respostas, que constituiu um passo crucial no percurso da investigação visto que forneceu uma lista de categorias e subcategorias necessárias para a interpretação e discussão dos discursos envolvidos no estudo. 
As falas foram agrupadas de acordo com as categorias gerais e suas unidades de análises. Para interpretar e analisar os dados optou-se pela análise do discurso. Isso significa dizer que se consideram os discursos produzidos pelos pesquisados “[...] uma unidade complexa - um todo que resulta de uma articulação - representando, assim, um conjunto de relações significativas individualizadas em uma unidade discursiva" (ORLANDI, 2007, p. 58).

Tomamos a técnica da análise do discurso para fundamentar a interpretação dos dados coletados nesta investigação por entender-se que o discurso constitui práticas sociais vivenciadas no seu cotidiano, visto que as pessoas o utilizam para pedir desculpas, acusar, justificar suas ações (GILL, 2002). Com efeito, o interesse do estudo pauta-se no texto em si mesmo, naquilo que está escrito, considerando os silêncios, gestos, inquietações e expressões captadas no momento das entrevistas, na qual pesquisador e pesquisado interagem com o objeto de estudo da pesquisa.

Assim, parte-se dos ditos e dos não ditos dos interlocutores envolvidos na investigação, no sentido de buscar espaços de interpretação, ricos em experiências concretas que envolvem a prática do supervisor no contexto escolar.

\section{Os achados do estudo: os ditos e os não ditos na voz dos interlocutores}

Neste estudo parte-se dos ditos e dos não ditos dos interlocutores envolvidos na investigação, no sentido de buscar espaços de interpretação, ricos em experiências concretas, entendendo a presença dos não ditos no interior do que foi dito (PÊCHEUX, 2008), sobre aspectos que envolvem a prática do supervisor no contexto escolar.

Desta forma, apresenta-se a seguir, uma descrição sucinta dos resultados recolhidos com os relatos destacando três aspectos: o primeiro diz respeito às concepções atribuídas pelos supervisores, diretores e professores à ação supervisora que contribuem para a transformação de práticas no contexto escolar. O segundo aspecto evidencia os indicadores que estimulam o olhar crítico/reflexivo dos professores. E o terceiro versa sobre a participação efetiva do supervisor e transformação da prática docente.

Vejam-se os relatos e as respectivas análises sobre as concepções atribuídas pelos supervisores, diretores e professores à ação supervisora:

[...] estão muito mais ligadas às questões burocráticas! Acompanhamento da parte administrativa (P-AGAR, D-POTÍFERA).

É aquela parte que vai supervisionar o andamento da escola no que diz respeito à parte docente, a parte discente, à parte administrativa. Em que se precisa melhorar (P-PUÁ). 
Nos trechos 1 e 2, podemos perceber que as interlocutoras fazem referência ao trabalho da supervisão como apoio administrativo. P-Agar e D-Potífera (Trecho 1) afirmam que as ações da supervisão [...] estão muito mais ligadas às questões burocráticas! Acompanhamento da parte administrativa. P-Puá (Trecho 2) diz que a supervisão É aquela parte que vai supervisionar o andamento da escola no que diz respeito à parte docente, à parte discente, a parte administrativa.

Nessas falas, fica evidente uma concepção de supervisão associada aos modelos das teorias administrativas que ainda influenciam as formas de desenvolver a ação supervisora nos ambientes escolares. Esses modelos consideravam os supervisores responsáveis em efetivar o processo de educação e ensino, obedecendo aos mesmos princípios estabelecidos a uma empresa (MEDINA, 2002; SAVIANI, 2002).

Outra concepção evidenciada no estudo: os interlocutores associam a ação supervisora à ideia de colaboração/ parceria. Os trechos extraídos das falas dos entrevistados apresentam-se a seguir:

Uma parceria entre professores, entre a direção e entre o próprio supervisor... Não é você está inspecionando! Você está fiscalizando! Mas é a parceria que deve existir dentro da escola... (SSARA).

Não no sentido de ser fiscalizador. Ele é para atuar junto aos demais profissionais da escola (SHADASSA).

Parceria professor/supervisor, supervisor/ aluno e supervisor/processo... Principalmente processo... Não no sentido de fazer por, mas fazer com.... (S-ZADOQUE).

Nos trechos 1 e 2, S-Sara e S-Hadassa associam a ação supervisora à ideia de parceria entre todos os agentes educacionais. Nessa perspectiva, a supervisão, que antes era concebida como atividade burocrática e fiscalizadora, se apresenta como uma ferramenta com possibilidade de intervir no processo ensino-aprendizagem através de uma relação dialógica entre todos os que fazem a escola.

O discurso de S-Zadoque (Trecho 3) remete, também, à supervisão escolar como uma função que envolve parceria e colaboração. Porém, o interlocutor vai além, acrescentando a ideia de processo para endossar que a ação supervisora não pode ser caracterizada como ajuda no sentido de fazer por, mas, fazer com..., mas um trabalho de colaboração com os demais agentes educacionais envolvidos no processo ensino e aprendizagem.

É possível perceber como os discursos dos interlocutores S-Sara, S-Hadassa e S-Zadoque estão impregnados pela ideologia produzida na relação entre homem e realidade natural e social, ou seja, entre sujeito e exterioridade (ORLANDI, 2009), visto que incorporaram os novos sentidos atribuídos à ação supervisora na escola. Isso ocorre porque no contexto sócio histórico o qual fazem parte, foram constituídas formações ideológicas que atribuem à prática educativa desse profissional 
um caráter participativo, devendo ser pautada "[...] em um processo formativo contínuo, com o desenvolvendo e a ampliação da consciência de todos os atores educativos da escola sobre seus compromissos como educadores: a melhoria do trabalho pedagógico na escola" (PLACCO; SOUZA, 2008, p. 26).

Assim, os discursos revelam que novos sentidos foram agregados à supervisão escolar, colocando o supervisor como sujeito ativo, agente de transformação capaz de fazer intervenções que pressupõem articulação entre as equipes administrativa, docente e a supervisora, desenvolvendo um trabalho coletivo que busca transformar as práticas no interior das escolas de EJA, garantindo êxito no processo ensino/ aprendizagem e, consequentemente, atingindo níveis de qualidade como preconiza o Parecer 11/ 2000 do Conselho Nacional de Educação (BRASIL, 2000). Com efeito, essas transformações das práticas constituem uma das formas de assegurar a efetivação da educação como direito a todos aqueles jovens e adultos que não tiveram acesso à escola na idade própria.

No que concerne aos indicadores de espaços utilizados pelo supervisor para estimular o olhar crítico e reflexivo dos professores, percebe-se no grupo de falas elencadas abaixo, que a ação do supervisor volta-se para a realização de atividades burocráticas. Veja-se o que dizem os interlocutores da investigação:

Ações mais concretas, livro didático para todo mundo, transporte a gente que gerencia... Esses macros problemas que existem na escola! Então por isso é necessária a atuação do supervisor [...] para que a escola cresça e para que o aluno aprenda! (S-Hadassa).

Eu vejo muito desvinculado o trabalho da orientação, da supervisão pedagógica do trabalho mesmo da sala de aula. Eu vejo mais preocupação em organizar, disciplinar. No trabalho efetivo da sala de aula com os alunos, eu não percebo! Ela faz alguns trabalhos que são mais da parte administrativa. E não de supervisão... Eu não vejo intervenção da supervisora no trabalho mesmo efetivo na sala de aula (P-Ester).

A gente tenta! A gente tenta fazer algo!... Às vezes, assumo determinadas atividades que fogem totalmente do trabalho... Então às vezes a gente está fazendo um papel mais abrangente do que só o de supervisor. À noite... Eu deixo o foco do meu trabalho para resolver um problema, que tem que ser resolvido! (S-Madalena).

No início de sua fala, S-Hadassa (Trecho 1) faz uma argumentação sustentada por sua experiência ao garantir que [...] gerencia... Esses macro problemas que existem na escola [...]. Os problemas a que se refere não estão incluídos nas suas atribuições, visto que, a questão de transporte é administrativa. O discurso de S-Hadassa deixa claro que assume determinadas ações que não são de sua competência ao afirmar: Então às vezes a gente está fazendo um papel mais abrangente do que só o de supervisor [...].

Sobre essa questão, Medina (2002, p.140) diz que os supervisores que centralizam suas intervenções “[...] no emergente, isto é, ficam disponíveis para atender aos imprevistos da escola concentram o seu trabalho no campo administrativo, desenvolvem atividades burocráticas 
tradicionalmente realizadas e aceitas pelos diretores das escolas". Dessa forma, ficam impedidos de obter avanços quanto à ressignificação de sua prática.

A P-Ester (Trecho 2) se manifesta sobre a questão afirmando ser: [...] muito desvinculado o trabalho da orientação, da supervisão pedagógica do trabalho mesmo da sala de aula e atribui isso à preocupação que a supervisora tem em [...] organizar, disciplinar [...] em realizar [...] alguns trabalhos que são mais da parte administrativa. E não de supervisão.

Assim, a professora avalia que a ação da supervisora está mais voltada para as atividades defendidas por Medina (2002), como emergentes, que surgem no cotidiano escolar, tornando-se o principal fator de impedimento de uma intervenção da supervisora no trabalho mesmo efetivo na sala de aula. Vale lembrar que a professora se coloca com o olhar voltado para seu contexto de atuação, a sala de aula.

Com efeito, o supervisor fica preso a afazeres administrativos deixa o foco do seu trabalho o que "[...] consequentemente resultará na redução de seu tempo, destinado às atividades diretamente ligadas à sua função" (GÉGLIO, 2009, p. 116) de acompanhar, orientar, garantir momentos de reflexão e investigação sobre a prática docente e isso é muito preocupante.

S-Madalena (Trecho 3), em um tom de angústia, afirma tentar [...] fazer algo! Que venha contribuir para o desenvolvimento profissional e pessoal dos professores [...]. Na tentativa de se justificar termina por reforçar em seu discurso que assume [...] determinadas atividades que fogem totalmente do trabalho [...]. O discurso evidencia que, em seu ambiente de trabalho, o supervisor realiza atividades que não são de sua competência e se vê executando múltiplas tarefas, que o afasta cada vez mais de suas atribuições na escola, ou seja, o gerenciamento das questões pedagógicas.

Isso revela a situação conflituosa vivenciada pelo supervisor, e no caso específico da EJA, o problema se agrava, visto que, S- Madalena, ao afirmar em seu discurso que: À noite... Eu deixo o foco do meu trabalho para resolver um problema, que tem que ser resolvido! , não deixa claro em seu texto, que trabalho é esse, e se o problema a ser resolvido, o afasta realmente de sua ação.

$\mathrm{Na}$ realidade o grande problema que deve ser enfrentado na escola pelo supervisor, é o pedagógico. Afastando-se deste, o foco de sua ação e assim:

[...] suas intencionalidades e seus propósitos são frustrados e suas circunstâncias o fazem responder à situação do momento, 'apagando incêndios' em vez de construir e reconstruir esse cotidiano, com vistas à construção coletiva do projeto políticopedagógico da escola (PLACCO, 2009, p. 47).

O discurso de P-Bate-Seba (Trecho 4), reconhece inicialmente que o supervisor contribui para estimular a prática docente. Classifica o supervisor como a pessoa que acompanha... No entanto se contradiz quando diz que nem sempre esse acompanhar dá certo [...] e justifica sua 
afirmação dizendo que o supervisor hoje [...] TEM tanta atribuição [...]. Utilizando um tom de denúncia afirma: [...] às vezes, parar com o professor mesmo, fica para $3^{\circ}, 4^{\circ}$ ou $5^{\circ}$ plano porque TEM tanta coisa.

Nesse contexto, volta-se a atenção para a palavra TEM. A forma como aparece no texto demonstra que o professor está convencido de que o problema não é do supervisor. Este, ao priorizar ações que fogem de sua competência, o trabalho pedagógico a ser desenvolvido fica como afirma P-Bate-Seba, em $3^{\circ}, 4^{\circ}$ ou $5^{\circ}$ plano. Este aspecto abre espaço para uma reflexão sobre as competências do supervisor na escola. Com esses argumentos, ousa-se afirmar que, diante da complexidade das questões pedagógicas que precisa enfrentar no dia a dia profissional, o supervisor se vê realizando múltiplas tarefas no sentido de responder às necessidades do contexto escolar, que embora façam parte da dinâmica institucional, não são de sua responsabilidade e não podem ser compreendidas inerentes à sua função (GÉGLIO, 2009).

Diante dessa discussão, percebe-se que a sobrecarga de trabalho, resultante do acúmulo de ações próprias da gestão escolar e do sistema, faz o supervisor assumir atribuições que não lhe competem e que ao mesmo tempo restringem a sua área de atuação, demonstrando falta de clareza sobre o seu objeto de trabalho. Além disso, ao admitir o envolvimento em tarefas imediatistas, questões técnico-burocráticas da escola, o supervisor representa na origem do discurso, dito e/ou não dito, a consciência de suas responsabilidades, sentimentos, finalidades esperadas e expectativas frustradas, (ORLANDI, 2009), representando, assim, como encaminha sua própria prática discursiva.

Ainda sobre os indicadores de espaços utilizados pelo supervisor para estimular o olhar crítico e reflexivo dos professores, obtiveram-se as seguintes respostas:

[...] Até procura fazer um trabalho mais dinâmico para melhorar o ensino aprendizagem, mas o que eu observo é de deixar o pedagogo trabalhar. [...] Porque tem muita resistência do professor. E tem muitos supervisores que tem propostas boas de melhorar a aprendizagem e o ensino (PHagite).

A supervisora... Ela tem tentado fazer isso. Mas ainda não é o que a gente gostaria porque falta o outro lado! ...O lado da receptividade dos professores de estarem atentando que esse é um momento importante (D-Asenate).

E... Eu não culpo nem tanto a direção, a supervisão... O professor às vezes é tão resistente! (PAgar).

[...] É comum você encontrar resistência quando você leva sugestões. Às vezes essas sugestões são entendidas como cobrança (P-Joás).

A pedagoga da noite, da EJA!...Coitada! É sofredora. Ela não tem tanta cobrança que a pedagoga do dia tem!...Esbarra em outro aspecto, rejeição do professor... Acha que ele já é formado, a pedagoga não tem condições de estar intervindo no papel dele, às vezes, escutam! Mas na hora de por em prática! (D-Raquel). 
Analisando o agrupamento de falas, percebe-se que mesmo reconhecendo que há resistência ao trabalho da supervisão, esse pensamento é externado de forma diferente. P-Agar, em tom nostálgico, transparecendo desânimo, lamenta a resistência do professor se colocando numa posição confortável, visto que, não toma partido mesmo afirmando que: O professor às vezes é tão RESISTENTE! Esta posição é evidenciada na palavra tanto colocada no texto com uma indefinição do que não foi dito, deixando claro no seu texto que: [...] não culpo nem TANTO a direção, a supervisão [...]. Com isso deixa de fazer uma análise crítica da ação supervisora na escola ou mesmo apontar sugestões que possam desencadear transformações na prática profissional tanto do supervisor quanto do próprio professor.

Já no discurso de P-Joás, a palavra resistência não se refere ao professor. O supervisor é que é resistente porque não aceita as sugestões que ele, professor, leva para a discussão, colocando uma barreira entre ambos. A falta de uma relação dialógica é evidente e isso prejudica o trabalho do supervisor e, consequentemente, do professor em sala de aula. O que não ocorre com P- Hagite, que reconhece a ação supervisora e a resistência dos professores em aceitar [...] propostas boas de melhorar a aprendizagem e o ensino. Ao mesmo tempo, deixa claro que há algo que impede o supervisor de desenvolver sua ação, evidenciando a falta de condições favoráveis para o trabalho do pedagogo no âmbito físico e social.

É interessante perceber que na visão do professor, falando do lugar que lhe confere a posição social do exercício da docência, admite não haver espaço para o supervisor realizar atividades que provoquem o olhar crítico do docente sobre a prática pedagógica, atribuindo esse fato, à resistência dos professores.

A visão dos gestores D-Asenate e D-Raquel (Trechos 2 e 5) também, aponta a resistência dos professores como a maior dificuldade encontrada pelo supervisor para desenvolver um trabalho, visando estimular o olhar crítico e reflexivo dos docentes. Raquel, ao se referir à supervisora do turno noturno, da EJA, inicia comparando o trabalho realizado no diurno com o noturno, dizendo que não existe [...] tanta cobrança que a pedagoga do dia tem!... Deixando claro que a supervisora não tem iniciativa e nem consegue motivar o professor, eles a escutam por educação é uma Coitada! É sofredora.

Esse posicionamento deixa claro que a supervisora não faz a mínima diferença na escola, pois, nem o professor e muito menos a direção acreditam no seu poder de atuação em frente às questões pedagógicas que porventura se apresentam. Além da falta de iniciativa, se depara com outra situação fundamental: a rejeição do professor [...] Este, segundo D-Raquel, Acha que ele já é formado, a pedagoga não tem condições de estar intervindo no papel dele às vezes, escutam! Mas na hora de pôr em prática! 
Na visão de D-Asenate, a supervisora da EJA até se esforça, mas não atinge o que a escola espera de sua ação e atribui a ela a dificuldade do professor compreender que esse é um momento importante e esta falta de compreensão se deve ao outro lado! ... O lado da receptividade dos professores. Com esse discurso, atribui ao supervisor a responsabilidade pela falta de receptividade do professor sintetizado na expressão: A supervisora... Ela tem TENTADO fazer isso.

Assim, nos tons implícitos nos recortes analisados, o supervisor é visto como coitado. Mesmo tentando realizar um trabalho no âmbito escolar, esbarra no conflito de saberes existentes no interior da escola. O professor acredita, por ser especialista em uma determinada área do conhecimento, que é detentor de um saber e por esta razão não precisa trocar experiências com os seus pares.

Contudo, não se pode esquecer que o conhecimento é socialmente construído e as maneiras como se compreende o mundo, por meio, das várias leituras e diversos olhares, são determinadas pelos processos sociais fortalecidos nas relações que se estabelecem com os outros (GILL, 2002).

Nessa perspectiva, ao trabalhar as relações interpessoais, o supervisor define seu espaço na escola, buscando a compreensão das “[...] tendências de tempo e movimento do outro, as necessidades de confronto e interlocução, num movimento da prática que se dá num continuum" (PLACCO, 2009. p. 55). Diante disso, é necessário que o supervisor desenvolva um trabalho de escuta e de respeito, que valorize os saberes advindos da experiência, a fim de vencer a resistência dos professores.

Assim, as estratégias utilizadas pelo supervisor para impulsionar sua prática merecem uma reflexão mais aprofundada, pois elas são o ponto de partida para a socialização de saberes científicos e experienciais que darão vida ao seu trabalho no contexto escolar, contribuindo para a constituição de espaços ancorados na confiança e respeito mútuo.

No que diz respeito ao último aspecto analisado, cujo foco foi a participação efetiva do supervisor e transformação da prática docente:

[...] O que ela está tentando fazer... É a questão de trazer palestras, pessoal de fora para ver se estimula se incentiva. Para ver se a evasão diminui... Ajudando o professor com seus planejamentos, na seleção de atividades diversificadas (P-ZERUIA).

[...] Assim de trabalhos diversificados. Traz uma ideia nova que acaba ajudando! (P-DÉBORA; PISCÁ).

Eu tento!....Dou um apoio maior... Com atividades diversificadas, com material... Todo material que eu tenho do dia, eu trago para a noite: fluxo de aula, sugestão de atividades, material que foi organizado para leitura de português, material que tem muitas sugestões de atividades. E aí a gente faz uma análise, faz escolhas, faz uma montagem, recorta para atender exatamente aquele nível dos alunos que estão com a leitura regular. (S-HADASSA). 
Com atividades coletivas no pátio, com os alunos envolvendo o professor nesse trabalho diferenciado, aulas mais atrativas. O aluno da educação de jovens e adultos, ele anda meio à margem (D-ASENATE).

Todas as falas apontam as atividades diversificadas como principal estratégia utilizada pelo supervisor para estimular a produção dos saberes docentes. P-Débora; P-Isca (Trecho 2) dizem sem muito convicção que os [...] trabalhos diversificados. Traz uma ideia nova que acaba ajudando. Entretanto, o seu discurso não convence o leitor e nem deixa claro se essa ajuda a que se refere favorece a aprendizagem do aluno.

Nesse sentido, P-Zeruia ao fazer uso da palavra tentando, afirma, em tom evasivo, que a preocupação em trazer alguém de fora para realizar palestra é motivada pela diminuição da evasão e em nenhum momento chama atenção para o verdadeiro sentido de se realizar em sala de aula atividades diversificadas, visto que estas se constituem em um conjunto de estratégias utilizadas pelo professor sob a orientação do supervisor, com a intencionalidade de atender às dificuldades da turma e permitindo que os alunos encontrem motivação e avanço no próprio processo de aprendizagem.

S-Hadassa (Trecho 3) tenta trazendo material utilizado pelos professores em outro contexto e com outros sujeitos, reafirmando que as peculiaridades dos jovens e dos adultos não são consideradas ao ser pensada uma prática pedagógica para este público. Assim, percebe-se nos ditos e não ditos da supervisora que ao trazer o material do dia para ser utilizado com pessoas jovens e adultas, preocupa-se em fazer [...] uma montagem, recorta para atender [...] aos interesses de quem? Dos alunos? Dos professores? Do próprio supervisor? Eis a grande questão a ser refletida.

D-Asenate (Trecho 4) confirma esta preocupação quando destaca que o aluno da EJA, anda meio à margem. Essa expressão é por si só, bastante reveladora e preocupante, pois fica claro que o supervisor, apesar de realizar algumas tentativas, ainda não tem conseguido desenvolver um trabalho que contribua para a produção de saberes e transformação de práticas pedagógicas na educação de pessoas jovens e adultas.

\section{Considerações finais}

A interpretação dos dados, apoiada na análise do discurso, possibilitou extrair nas falas de professores, diretores e supervisores, sujeitos desta investigação, as maneiras de significar, considerando a produção de sentidos como parte de suas vidas, visto que os discursos sempre têm relação com o contexto histórico de atuação do sujeito.

Diante dos resultados obtidos, constatamos a coexistência de diferentes concepções sobre a ação supervisora na escola: aquelas que a concebem como um componente articulado responsável 
em dinamizar e acompanhar a prática pedagógica docente, através de um trabalho de colaboração/parceria e aquelas concepções que associam a ação supervisora à ideia de apoio administrativo, burocracia, geralmente resultantes da realização de atribuições que não lhe competem, ocasionando a indefinição quanto ao seu objeto de trabalho e principalmente restringindo a sua contribuição para a transformação das práticas desenvolvidas na escola.

A realização de atividades burocráticas e a resistência dos professores foram apontadas como os principais empecilhos encontrados pela ação supervisora para promover momentos estimuladores da reflexão sobre a prática docente. Evidenciando que a ação do supervisor não tem conseguido fomentar o processo reflexivo-formativo no contexto escolar. Diante disso, a ação supervisora necessita de mudanças no sentido de conquistar a confiança dos professores e diretores, enfim, da escola.

Quanto à participação efetiva do supervisor e transformação da prática docente os dados revelam que as atividades diversificadas foram apontadas, pelos interlocutores do estudo, como principal estratégia utilizada pelo supervisor para estimular a socialização de saberes científicos e experienciais. Essas discussões demonstram que, apesar de realizar algumas tentativas, a ação do supervisor ainda se volta para resoluções de problemas pontuais, executando múltiplas tarefas que não são de sua competência, e com isso, não tem conseguido desenvolver um trabalho que contribua para a produção de saberes e transformação de práticas pedagógicas na educação de pessoas jovens e adultas.

Tomando como referência o estudo realizado, percebe-se que a ação supervisora no contexto escolar não tem conseguido fomentar ou apoiar o processo reflexivo-formativo visto que é marcada pela realização de ações pontuais e atividades burocráticas /administrativas. Diante disso, é necessário mudanças na sua atuação no sentido de conquistar a confiança dos professores e diretores, enfim, da escola, no sentido de superar dificuldades e construir espaços de reflexão das questões pedagógicas visando à qualidade do ensino e da aprendizagem.

Outro indicador demonstrou a necessidade sentida pelos professores de intervenções, por parte da supervisão, que suscitem a problematização sobre a prática e estimulem a busca de saberes e reflexões sobre novas técnicas e formas de ensinar.

Diante disso, reafirma-se a importância de se oportunizar aos professores espaços de formação continuada, acompanhada e estimulada pelas ações do supervisor escolar, a fim de identificar as necessidades, as dificuldades e possibilidades da realidade educacional à luz de projetos de trabalhos coletivos.

Estes projetos devem ser realizados principalmente no ambiente escolar, assegurando a valorização dos educadores de pessoas jovens e adultas através do respeito e da escuta de suas 
ideias, receios, expectativas e saberes construídos a partir de sua experiência profissional. Assim como Nóvoa (1995), acredita-se que supervisores e professores vivem em tempos difíceis e paradoxais, deles se exigem competências profissionais para lidar com a complexidade de problemas com que se deparam constantemente no contexto da sala de aula e, porque não dizer no contexto escolar.

Refletir sobre os ditos e não ditos à luz da análise do discurso foi tarefa instigante, pois o movimento constante de ir e vir entre a teoria e a empiria provocou a oportunidade de lançar olhares sobre a ação supervisora na escola e intervenções que estimulem a busca de saberes necessários para a transformação da prática do supervisor, visando otimizar o processo ensino/aprendizagem, sobretudo dos docentes que atuam com pessoas jovens e adultas.

\section{Referências}

ALARCÃO, Isabel. Do olhar supervisivo ao olhar sobre a supervisão. In: RANGEL, Mary. Supervisão pedagógica: princípios e práticas. Campinas, SP: Papirus, 2004. p. 11-55.

TAVARES, José. Supervisão da prática Pedagógica: uma perspectiva de desenvolvimento e aprendizagem. Coimbra-Portugal: Almedina, 2003.

ALONSO, Myrtes. A Supervisão e o desenvolvimento profissional do professor. In: FERREIRA, Naura. Syria Carapeto (Org.). Supervisão educacional para uma escola de qualidade: da formação à ação. 3. ed. São Paulo: Cortez, 2002. p. 167-181.

AMARAL, M ária João; MOREIRA, Maria; RIBEIRO, Deolinda. O papel do supervisor no desenvolvimento do professor reflexivo. In: ALARCÃO, I. (Org.) Formação reflexiva de professores: estratégias de supervisão. Porto: Porto, 1996. p. 89-122.

BRASIL. Educação de jovens e adultos - parâmetros em ação. Secretaria de Educação Fundamental. Programa de desenvolvimento profissional continuado / Ministério da Educação. Brasília: A Secretaria, 1999.

Conselho Nacional de Educação. Câmara de Educação Básica. Diretrizes Curriculares Nacionais para Educação de Jovens e Adultos. Brasília-DF. Parecer 11/ 2000.

BRITO, Antonia Edna. Sobre a formação e a prática pedagógica: o saber, o saber-ser e o saber-fazer no exercício profissional. Revista Linguagens, Educação e Sociedade. Teresina, n. 12, p. 45-52, jan/jun, 2005.

GÉGLIO, Paulo César. O papel do coordenador pedagógico na formação do professor em serviço. In: ALMEIDA, Laurinda Ramalho; PLACCO, Vera. Maria Nigro de Souza. O coordenador pedagógico e o cotidiano da escola. 6. ed. São Paulo: Edições Loyola, 2009, p. 113 - 120.

GÓMEZ PÉREZ, A. I. Formar professores como profissionais reflexivos. In: NÓVOA, A. Os professores e sua formação. Lisboa: Dom Quixote, 1998. 
FERREIRA, Naura Syria Carrapeto. Supervisão educacional: novas exigências, novos conceitos, novos significados. In: RANGEL, Mary. Supervisão pedagógica: princípios e práticas. CampinasSP: Papirus, 2004. p. 81- 102.

FILIPKOWSKI, Mariléia Lilian. Do cotidiano percebido à ação supervisora: encaminhamentos para a formação continuada. Revista Olhar de Professor. Ponta Grossa, v.6, n 1, p. 41-58, 2003.

FRANCO, Francisco Carlos. O coordenador pedagógico e a questão do protagonismo juvenil. In: ALMEIDA, Laurinda Ramalho; PLACCO, Vera Maria Nigro de Souza (Org.). O coordenador pedagógico e questões da contemporaneidade. São Paulo: Loyola, 2009. p. 61-80.

GILL, Rosalind. Análise de discursos. In: BAUER, Martin W; GASKELL, George. Pesquisa qualitativa como texto, imagem e som: manual prático. Petrópolis, Vozes, 2002.

MEDINA, Antonia da Silva. Supervisão escolar: da ação exercida à ação repensada. Porto Alegre: Edipucrs, 2002.

MOURA, Maria da Glória Carvalho. Teorizando a prática, construindo a teoria, um diálogo com a incerteza: desafios para o professor da Educação de jovens e adultos. Natal, 2006 a. 317f. Tese (Doutorado em Educação) Universidade Federal do Rio Grande do Norte, Rio Grande do Norte, 2006.

NÓVOA, Antonio. Os professores e o "novo" espaço público da educação. In: TARDIF, Maurice; LESSARD, Claude (Org.). O Ofício de professor: história, perspectivas e desafios internacionais. Trad. Lucy Magalhães. Petrópolis- RJ: Vozes, 2008. p. 217- 233.

Os professores e a sua formação. Lisboa: Dom Quixote, 1995.

LIVEIRA, Marli. M. Como fazer pesquisa qualitativa. Petrópolis-RJ: Vozes, 2007.

ORLANDI, Eni Puccinelli. Análise de discurso: princípios e fundamentos. 8. ed. Campinas: Pontes, 2009.

A análise de discurso em suas diferentes tradições no Brasil. In: INDURSKY, Freda; FERREIRA, Maria Cristina Leandro Ferreira (Org.). Michel Pêcheux e análise do discurso: uma relação de nunca acabar. São Paulo: Clara Luz, 2007. p. 75-87.

PACHECO, José. Escola da ponte: transformação da educação. Petrópolis-RJ: Vozes, 2008.

PÊCHEUX, Michel. O discurso: estrutura ou acontecimento. Trad. Eni Puccinelli Orlandi. 5. ed. Campinas: Pontes, 2008.

LACCO, Vera. Maria. Nigro. de S. O coordenador pedagógico no confronto com o cotidiano da escola. In: ALMEIDA, Laurinda Ramalho; PLACCO, Vera. Maria. N. de Souza; ALMEIDA, Laurinda Ramalho de (Org.). O coordenador pedagógico e o cotidiano da escola. 6. ed. São Paulo: Loyola, 2009, p. $47-60$.

; SOUZA, Vera Lucia Trevisan de. Desafios ao coordenador pedagógico no trabalho coletivo da escola: intervenção ou prevenção? In: ALMEIDA, Laurinda Ramalho; PLACCO, Vera. Maria. N. de Souza; ALMEIDA, Laurinda Ramalho de (Org.). O coordenador pedagógico e os desafios da educação. 6. ed. São Paulo: Loyola, 2008, p. 25- 30. 
RANGEL, Mary. Supervisão: do sonho à ação-uma prática em transformação. In: FERREIRA, Naura. Syria. Carrapeto (Org.). Supervisão educacional para uma escola de qualidade: da formação à ação. 3. ed. São Paulo: Cortez, 2002. p. 69-96.

SAVIANI, Demerval. A Supervisão Educacional em Perspectiva Histórica: da função à profissão pela mediação da idéia. In: FERREIRA, Naura Siria. C. (Org.). Supervisão educacional para uma escola de qualidade: da formação à ação. 3. ed. São Paulo: Cortez, 2002.

Recebido em: 30.07.2014

Aceito em: 09.10.2015 